\title{
KESIAPAN GEREJA-GEREJA ANGGOTA SINODE GKJ DALAM PENERAPAN RENCANA OPERASIONAL SISTEM INFORMASI MANAJEMEN TERPADU
}

\author{
Restyandito $^{1^{*}}$, Budi Susanto ${ }^{2}$, Umi Proboyekti ${ }^{3}$, Gloria Virginia ${ }^{4}$ \\ 1,2,3,4 Fakultas Teknologi Informasi, Universitas Kristen Duta Wacana \\ Jl. Dr. Wahidin Sudirohusodo No.5-25, Kotabaru, Gondokusuman, Yogyakarta 55224 \\ Email: ${ }^{1}$ dito@ti.ukdw.ac.id; ${ }^{2 b u d s u s @ t i . u k d w . a c . i d ; ~}{ }^{3}$ othie@si.ukdw.ac.id; ${ }^{4}$ virginia@ti.ukdw.ac.id \\ * Penulis korespondensi
}

\begin{abstract}
Abstrak: Sinode GKJ menyadari bahwa Teknologi Informasi dan Komunikasi harus dimanfaatkan secara optimal untuk mendukung pelayanan di Sinode, Klasis, maupun setiap Gereja-gereja Kristen Jawa. Seperti yang telah tertuang dalam dokumen Rencana Operasional (Renop) penerapan Rencana Strategis Pengembangan Sistem Informasi Manajemen Terpadu (Renstra SIMT) Sinode GKJ, pada periode 2019 telah ditetapkan untuk pembaruan infrastruktur dan web Sinode GKJ. Tim menyadari bahwa sumber daya manusia yang ada saat ini tidak mencukupi untuk melaksanakan Renop yang telah ditetapkan. Oleh sebab itu tahap awal dari penerapan Renstra Pengembangan SIMT adalah memetakan kondisi infrastruktur dan kesiapan gerejagereja dan klasis di lingkungan Sinode GKJ. Berdasarkan hasil pemetaan tersebut tim dapat melakukan pelatihan dan pembekalan yang diperlukan agar penerapan Renstra Pengembangan SIMT dapat terlaksana dengan baik. Hasil awal yang diperoleh dari 49 sampel gereja menunjukkan bahwa ukuran jemaat mempengaruhi kesiapan gereja. Juga ditemukan bahwa aksesibilitas ke teknologi informasi (seperti ketersediaan komputer dan internet) tidak mencerminkan kesiapan gereja karena yang diperlukan dalam memanfaatkan teknologi informasi adalah perubahan paradigma dalam perilaku organisasi dan kesiapan sumber daya manusia yang ada.
\end{abstract}

Kata kunci: Kesiapan organisasi, teknologi informasi, gereja, sumber daya manusia

\begin{abstract}
The GKJ Synod realizes that Information and Communication Technology must be used optimally to support services in the Synod, and their church members. As stated in the Operational plan document (Renop) of Development Strategic Plan for the Integrated Management Information System (Renstra SIMT) of the GKJ Synod, in the 2019 period it has been established for infrastructure updates and the GKJ Synod web site. The team is aware that the current human resources in each church differs and their capability may not suffice to implement the Renop that has been determined. Therefore, the initial stage of the implementation of the SIMT Development Strategic Plan was to map the condition of the infrastructure and the readiness of the churches within the GKJ Synod. Based on the results, team can conduct training needed so that the implementation of the SIMT can be carried out properly. The initial result based on the sampling from 49 churches confirmed that the size of congregation affects the readiness of the church. It is also found that accessibility to information technology (such as computer and internet availabiltiy) does not reflect church readiness as paradigm shift in organization behavior is needed in utilize information technology.
\end{abstract}

Keywords: Organization readiness; information technology; church; human resources.

\section{PENDAHULUAN}

Teknologi Informasi telah menembus hampir semua aspek kehidupan manusia sehari-hari sehingga hubungan yang terkait dengan individu dan organisasi diaktifkan dan dimediasi secara digital (Murumba \& Omuya, 2017). Gereja tidak luput dari dampak perkembangan Teknologi Informasi tersebut. Pemanfaatan Sistem Informasi dipandang dapat meningkatkan kinerja Gereja dalam melayani kebutuhan jemaat, diseminasi informasi maupun operasional organisasi yang lebih efektif dan efisien. (Sagala, Sadikin, \& Irawan, 2018; Pakpahan, Siagian \& Ulyreke, 2019). 
Oleh sebab itu Sinode Gereja-gereja Kristen Jawa (Sinode GKJ) memandang perlu dibuatnya suatu Sistem Informasi Manajemen Terpadu yang dapat memenuhi kebutuhan organisasi Sinode maupun Gereja-gereja yang tergabung di dalam sinode. Oleh sebab itu, sejak tahun 2018 Badan Pelaksana Sinode dan Badan Pengawas Sinode GKJ telah bekerjasama dengan Fakultas Teknologi Informasi Universitas Kristen Duta Wacana untuk membuat Rencana Induk Pengembangan Sistem Informasi Manajemen Terpadu (Restyandito, et al., 2018). Sistem Informasi Manajemen Terpadu menjadi suatu hal yang penting, karena saat ini beberapa gereja telah mengembangkan sistem informasi untuk memenuhi kebutuhan mereka, tapi karena tidak adanya rencana pengembangan sistem informasi yang komprehensif, masing-masing gereja membuat sistem yang berdiri sendiri-sendiri sehingga jika dibutuhkan sharing data/sumber daya sistem tersebut tidak dapat saling terhubung dengan maksimal.

Setelah dokumen RIP SIMT Sinode GKJ berhasil dibuat, tahap selanjutnya adalah pengimplementasian rencana tersebut agar tujuan dibuatnya SIMT tersebut dapat tercapai. Sinode GKJ terdiri dari 332 Gereja yang tergabung dalam 32 klasis tersebar di seluruh pulau Jawa. Persebaran letak geografis tersebut menimbulkan beberapa masalah, diantaranya dalam hal komunikasi, diseminasi informasi, dan data/resource sharing. Selain itu Sinode GKJ memiliki basis pelayanan pedesaan, oleh sebab itu masih banyak gereja-gereja yang berada di kota kecil atau desa dengan keterbatasan infrastruktur maupun sumber daya manusia. Oleh sebab itu pelu dibuat pemetaan mengenai kondisi gereja anggota Sinode GKJ untuk mengetahui kesiapan gereja tersebut dalam mengimplementasikan Rencana Induk Pengembangan SIMT Sinode GKJ yang telah disepakati. Jika terdapat gerejagereja yang kondisinya belum mendukung penerapan SIMT tersebut maka pihak gereja dan Sinode perlu memikirkan pengadaan sumber daya yang dibutuhkan, demikian juga untuk sumber daya manusia yang ada perlu mendapatkan pelatihan yang diperlukan untuk dapat menggunakan SIMT yang akan dibuat tersebut. Masalah lain yang perlu diperhatikan adalah perubahan budaya organisasi dimana gereja-gereja masih melakukan manajemen organisasi secara manual, menjadi budaya digital dengan memanfaatkan teknologi dan collaborative tool.

Pemetaan infrastruktur dan kesiapan sumber daya manusia harus dilakukan untuk memberikan gambaran situasi klasis, gereja maupun pos pelayanan di lingkungan Sinode GKJ. Dengan memahami kondisi yang ada di lapangan maka dapat diambil langkah persiapan yang diperlukan agar penerapan SIMT Sinode GKJ dapat berjalan sesuai dengan yang direncanakan. Jika sumber daya manusia belum memiliki pengalaman menggunakan suatu sistem informasi maka perlu diberikan pelatihan yang sesuai dengan latar belakang pengguna.

Selain pelatihan untuk mempersiapkan sumber daya manusia yang ada, pemetaan yang dilakukan juga dapat digunakan sebagai sarana sosialisasi sistem informasi yang akan dibangun oleh Sinode GKJ, sehingga dengan adanya sosialisasi tersebut diharapkan tidak terjadi resistensi dari klasis, gereja dan pos pelayanan di lingkungan Sinode terhadap rencana pengembangan SIMT tersebut.

\section{METODE PELAKSANAAN}

Pendekatan yang digunakan untuk melakukan pemetaan kesiapan gereja dalam penggunaan sistem informasi adalah penelitian deskriptif dan kualitatif. Penelitian deskriptif sering digunakan untuk menjelaskan karakteristik suatu populasi atau fenomena yang dipelajari (Shields, \& Rangarajan, 2013). Penelitian deskriptif digunakan untuk menjawab apa karakteristik populasi yang dipelajari (what question), bukan bagaimana/mengapa suatu karakteristik terjadi (how/when/why question).

Metode yang digunakan adalah penyebaran kuesioner untuk mendapatkan gambaran kebutuhan dan kondisi gereja dan klasis untuk kesiapan Sistem Informasi. Kuesioner diedarkan online dalam bentuk Google Form maupun tercetak yang dikirimkan melalu pos. Pemilihan media online maupun cetak ini ditujukan untuk mengakomodasi kondisi gereja yang belum terbiasa menggunakan teknologi atau terkendala keterbatasan infrastruktur jaringan di daerahnya. Dari kuesioner yang disebarkan, diperoleh data dari 4 klasis dan 49 gereja. Menurut Gay dan Diehl (1992), ukuran sampel penelitian yang dibutuhkan untuk penelitian deskriptif sekurang-kurangnya sebesar $10 \%$ dari total elemen populasi. Sinode GKJ terdiri dari 332 gereja yang tergabung dalam 32 klasis, sehingga data yang diperoleh telah memenuhi syarat minimal 10\% yang disarankan oleh Gay dan Diehl. Selain itu, responden gereja yang mengisi kuesioner berasal dari 19 klasis yang ada (59\%) yang berada di kota besar maupun desa, sehingga data yang diperoleh dapat diasumsikan telah mewakili gambaran kondisi dan kesiapan gereja-gereja di lingkungan Sinode Gereja-gereja Kristen Jawa. Tabel 1 menunjukkan data responden klasis dan gereja yang mengisi kuesioner yang diedarkan.

Selain itu diadakan fokus group discussion (FGD) untuk kendala, hambatan dan harapan dari 
stakeholder Sistem Informasi yang akan dibuat. FGD dan wawancara merupakan salah satu metode yang sering digunakan dalam penelitian kualitatif (Gill, et al., 2008). Metode ini digunakan untuk menjalin keterbukaan, kepercayaan, dan memahami persepsi, sikap, serta pengalaman yang dimiliki oleh peserta dalam mengelola data jemaat, menyebarkan informasi dan penggunaan teknologi informasi. Metode ini telah digunakan oleh tim dalam pembuatan sistem pada organisasi gereja yang lain dan terbukti dapat memberikan hasil yang memuaskan (Virginia, et al., 2018). FGD diadakan dengan dihadiri oleh perwakilan gereja (10 gereja ), klasis (1 klasis) dan Sinode.

Tabel 1. Responden Kuesioner Kondisi dan Kesiapan Klasis dan Gereja

\begin{tabular}{|c|c|c|}
\hline No & Klasis & Jumlah \\
\hline 1 & Gunung Kidul & 1 \\
\hline 2 & Jakarta Bagian Timur & 1 \\
\hline 3 & Wonogiri & 1 \\
\hline 4 & Yogyakarta Bagian Selatan & 1 \\
\hline \multicolumn{2}{|r|}{ Total responden Klasis } & 4 \\
\hline No & Gereja (berdasarkan Klasis) & Jumlah \\
\hline 1 & Banyumas Bagian Selatan & 2 \\
\hline 2 & Banyumas Bagian Utara & 3 \\
\hline 3 & Blora-Bojonegoro & 1 \\
\hline 4 & Boyolali & 3 \\
\hline 5 & Citanduy & 6 \\
\hline 6 & Gunung Kidul & 1 \\
\hline 7 & Klaten Bagian Timur & 1 \\
\hline 8 & Pekalongan & 2 \\
\hline 9 & Pekalongan Bagian Barat & 2 \\
\hline 10 & Purwodadi & 1 \\
\hline 11 & Sala & 1 \\
\hline 12 & Salatiga Bagian Utara & 1 \\
\hline 13 & Semarang Bagian Barat & 4 \\
\hline 14 & Semarang Bagian Selatan & 2 \\
\hline 15 & Sragen & 1 \\
\hline 16 & Sukoharjo & 1 \\
\hline 17 & Wonogiri & 9 \\
\hline 18 & Yogyakarta Bagian Selatan & 2 \\
\hline 19 & Yogyakarta Bagian Utara & 6 \\
\hline & Total responden Gereja & 49 \\
\hline
\end{tabular}

\section{HASIL DAN PEMBAHASAN}

Kuesioner yang disebarkan terdiri dari 31 pertanyaan yang diharapkan dapat memberikan gambarakan mengenai gereja (jumlah jemaat, lokasi, sumber daya manusia, dsb.), peralatan pendukung (infrastukkur jaringan, ketersediaan komputer, dsb.) pengelolaan data warga (media pendataan, update data, dsb.), arsip dan pengarsipan (jenis informasi yang diarsipkan, cara pengarsipan, frekuensi pengarsipan, dsb.), serta publikasi informasi (jenis informasi yang dipublikasikan, media diseminasi, dsb.). Hasil kuesioner yang diperoleh dapat dilihat pada Gambar 1. Secara keseluruhan, $86 \%$ gereja memiliki kondisi yang sudah baik, $18 \%$ gereja memiliki kondisi cukup, dan hanya $2 \%$ gereja yang berada dalam kategori sangat baik. Hal ini merupakan awal yang baik untuk menerapkan SIMT di lingkungan gereja-gereja anggota Sinode GKJ.

Gambar 2 menunjukkan lebih detil kondisi dari gereja dilihat dari beberapa bidang. Tampak bahwa dari segi kesiapan peralatan pendukung komputer maupun infrastruktur banyak gereja yang sudah masuk dalam kategori sangat baik (32\%) dan baik (16\%), hanya sedikit yang masih masuk dalam kategori cukup (5\%). Hal ini menunjukkan bahwa pengadaan teknologi (komputer) sudah bukan merupakan kendala utama, karena kemajuan teknologi telah mengakibatkan harga yang semakin terjangkau bagi gereja. Demikian pula pembangunan infrstruktur yang cukup pesat oleh pemerintah mengakibatkan masalah konektivitas bukan merupakan hal yang patut dikuatirkan saat ini.

\section{SKOR TOTAL}

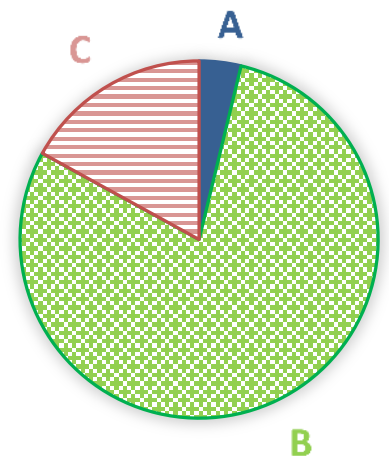

Gambar 1. Pengkategorian Kondisi Klasis/Gereja Secara Keseluruhan (A: Sangat baik, B: Baik, C: Cukup, D: Kurang, E: Buruk)

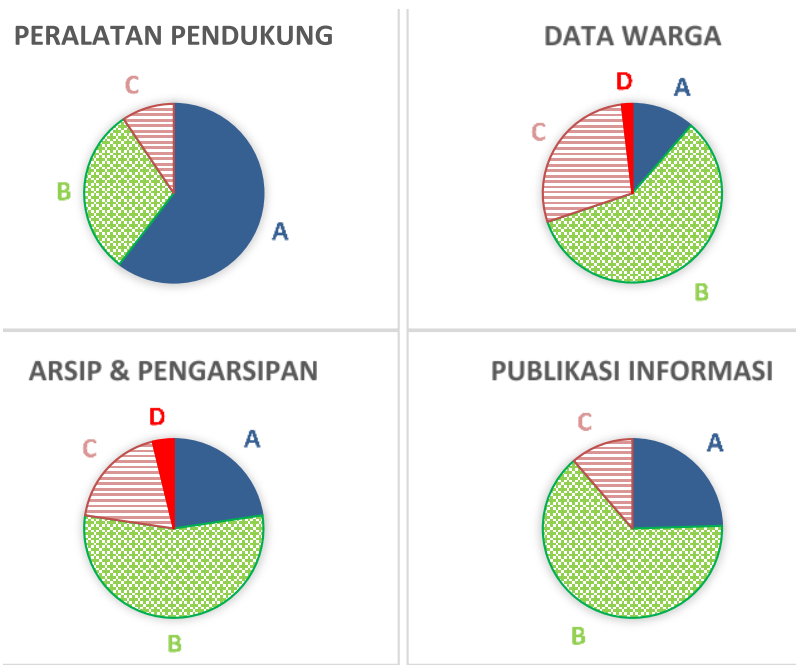

Gambar 2. Pengkategorian Kondisi Klasis/Gereja berdasarkan bidang (A: Sangat baik, B: Baik, C: Cukup, D: Kurang, E: Buruk) 
Namun jika dilihat lebih dalam pada kategori data warga, arsip \& pengarsipan dan publikasi informasi, tampak bahwa mayoritas kondisi gereja di lingkungan Sinode GKJ berada di kategori baik (Data Warga 63\%, Arsip \& Pengarsipan 59\%, Publikasi Informasi 69\%), bahkan untuk beberapa bidang ada yang masuk kategori kurang (Data Warga 2\%, Arsip dan Pengarsipan 4\%). Hal ini menyiratkan bahwa walaupun gereja dapat memiliki komputer belum tentu mereka memiliki budaya kerja yang baik yang dapat mendukung pengimplementasian SIMT di lingkungan Sinode GKJ.

Untuk mendapatkan gambaran yang lebih mendalam mengenai kondisi gereja, maka dilakukan single factor analysis of variance (ANOVA) antara kategori kondisi dan kesiapan gereja dengan besar/kecilnya gereja berdasarkan jumlah jemaat. Tabel 2 merupakan hasil analisa single factor ANOVA untuk mengetahui keterkaitan antara jumlah jemaat gereja dengan skor kondisi dan kesiapan gereja. Jemaat yang banyak diasumsikan sebagai gereja besar dan sebaliknya, jemaat yang sedikit diasumsikan sebagai gereja kecil. Dapat dilihat bahwa terdapat perbedaan yang signifikan secara statistik $(\mathrm{p}<0.05)$ terhadap skor kondisi dan kesiapan gereja dilihat dari besar kecilnya gereja. Gereja-gereja yang besar memiliki rata-rata nilai yang lebih baik (29.42) dibandingkan gereja-gereja yang kecil (24.05). Hal ini tentu tidak mengherankan mengingat gereja yang besar (jumlah jemaat yang banyak) dapat diasumsikan memiliki sumber daya keuangan maupun sumber daya manusia yang lebih baik dibandingkan gereja yang kecil.

Tabel 2. Analisa ANOVA Terhadap Kondisi Gereja Berdasarkan Jumlah Jemaat (Kategori 1: > 1000, 2: 500999, 3: 250-499, 4: 0-249)

\begin{tabular}{|c|c|c|c|c|c|c|}
\hline \multicolumn{5}{|l|}{ SUMMARY } & & \\
\hline Groups & Count & Sum & Average & Variance & & \\
\hline Kategori 1 & 7 & 206 & 29.42 & 3.952381 & & \\
\hline Kategori 2 & 16 & 444.5 & 27.78 & 7.232292 & & \\
\hline Kategori 3 & 15 & 393 & 26.20 & 8.457143 & & \\
\hline Kategori 4 & 11 & 264.5 & 24.05 & 11.82273 & & \\
\hline \multicolumn{7}{|l|}{ ANOVA } \\
\hline $\begin{array}{c}\text { Source of } \\
\text { Variation } \\
\end{array}$ & $S S$ & $d f$ & $M S$ & $F$ & P-value & F crit \\
\hline \multicolumn{7}{|l|}{ Between } \\
\hline $\begin{array}{l}\text { Groups } \\
\text { Within Groups } \\
\text { Total }\end{array}$ & $\begin{array}{l}152.0822 \\
368.8259 \\
520.9082\end{array}$ & $\begin{array}{r}3 \\
45 \\
48\end{array}$ & $\begin{array}{l}50.69408 \\
8.196132\end{array}$ & 6.185122 & 0.001305 & 2.811544 \\
\hline
\end{tabular}

Selanjutnya dilakukan uji korelasi untuk melihat hubungan antara ketersediaan peralatan (infrastruktur) dengan masing-masing bidang yang hasilnya dapat dilihat pada Tabel 3.

Tampak bahwa memang tidak ada korelasi yang kuat antara ketersediaan alat dengan kondisi gereja dalam pendataan warga, pengarsipan maupun publikasi informasi. Hal ini disebabkan karena keterbatasan sumber daya yang tidak memadai, baik dari segi ketersediaan tenaga gereja yang mengurusi bidang pendataan warga, pengarsipan atau publikasi informasi, maupun kemampuan tenaga gereja dalam menggunakan teknologi yang tersedia. Selain itu budaya kerja atau organisasi juga mempengaruhi tingkat kesiapan gereja dalam memanfaatkan teknologi informasi. Hal ini mengakibatkan layanan gereja tidak maksimal, sebagai contoh, walaupun sudah tersedia basis data jemaat, namun ditemui banyak data jemaat yang sudah tidak up-to-date (karena meninggal, pindah, atestasi, dll). Demikian juga proses pengarsipan dokumendokumen yang tidak dilakukan secara berkala mengakibatkan tidak semua dokumen gereja tersimpan dalam sistem arsip gereja.

Tabel 3. Uji korelasi ketersediaan peralatan dengan masing-masing bidang

\begin{tabular}{|c|c|c|}
\hline & Peralatan & Data Warga \\
\hline Peralatan & 1 & 0.328563 \\
\hline \multirow[t]{2}{*}{ Data Warga } & 0.328563 & 1 \\
\hline & Peralatan & Arsip \\
\hline Peralatan & 1 & 0.4741791 \\
\hline \multirow[t]{2}{*}{ Arsip } & 0.4741791 & 1 \\
\hline & Peralatan & $\begin{array}{l}\text { Publikasi } \\
\text { Informasi }\end{array}$ \\
\hline Peralatan & 1 & 0.2966091 \\
\hline Publikasi Informasi & 0.2966091 & 1 \\
\hline
\end{tabular}

Dari hasil FGD didapati bahwa gereja menyadari kebutuhan akan sistem informasi. Hanya 27\% dari gereja peserta FGD yang hadir mengatakan telah memiliki sistem informasi sendiri. Banyak gereja mengemukakan sulitnya melakukan update data (45\%), kondisi ini dialami baik oleh gereja yang telah memiliki sistem informasi maupun tidak. Hal ini menunjukkan bahwa peranan sumber daya manusia dan standar operasional prosedur merupakan hal yang harus dibenahi apabila Sinode GKJ akan menerapkan SIMT di lingkungan anggotanya. Oleh sebab itu, dalam beberapa bulan ke depan tim akan memberikan pelatihan-pelatihan yang diperlukan untuk membekali sumber daya manusia yang ada di gereja-gereja. Pelatihan yang direncanakan untuk tahap pertama adalah pelatihan penggunaan online collaborative tool untuk mengubah paradigma gereja dalam pemanfaatan teknologi.

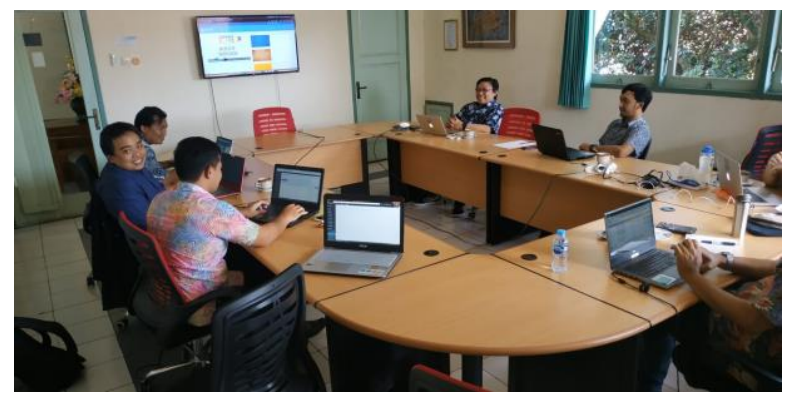

Gambar 3. Suasana pertemuan tim pengembangan SIMT Sinode GKJ 
Beberapa hal yang menjadi catatan dari FGD dengan perwakilan gereja yang dihadiri oleh majelis, pendeta dan karyawan gereja tersebut diantaranya:

1. Kesadaran sistem dimulai dari pendeta.

2. Tenaga kantor yang kurang merasa perlunya sistem dan merasa cukup dengan data manual.

3. Belum mengetahui manfaat yang diperoleh dengan adanya Sistem Informasi Terpadu yang dapat berbagi data antar gereja maupun antara gereja dan Sinode.

Oleh karena itu jika pihak Sinode GKJ berharap SIMT yang dibuat dapat diadopsi dan bermanfaat bagi anggotanya, pihak Sinode GKJ harus proaktif dalam melakukan sosialisasi dan juga terus melibatkan anggota dalam pembangunan SIMT agar kebutuhan anggota dapat terpenuhi.

\section{SIMPULAN DAN REKOMENDASI}

Kegiatan pengabdian masyarakat yang dilakukan oleh tim dari Fakultas Teknologi Informasi Universitas Kristen Duta Wacana dengan Sinode GKJ telah berhasil memetakan kondisi dan kesiapan gereja anggota Sinode GKJ dalam mewujudkan SIMT. Hasil pemetaan yang diperoleh melalui kuesioner ini merupakan tahap awal untuk memperoleh gambaran situasi gereja anggota Sinode GKJ. Dari hasil sampling terhadap 4 klasis dan 49 gereja, diperoleh gambaran bahwa $65 \%$ responden telah memiliki kesiapan dalam hal infrastruktur (sangat baik), namun hal ini tidak diikuti dengan kesiapan sumber daya manusia maupun budaya organisasi dimana hanya $12-27 \%$ gereja yang siap (sangat baik) dalam hal pengelolaan data warga, pengarsipan dan diseminasi informasi.

Langah selanjutnya adalah mendapatkan gambaran yang lengkap dari seluruh gereja anggota Sinode GKJ dengan mendorong agar gereja-gereja yang belum mengisi kuesioner dapat melengkapi kuesioner yang telah dikirimkan. Dari hasil pemetaan tersebut akan dibuat program-program pelatihan dan pendampingan sesuai kondisi gereja tersebut. Proses pemetaan ini berjalan paralel dengan pengembangan SIMT Sinode GKJ, dengan demikian diharapkan pada saat SIMT Sinode GKJ telah siap diaplikasikan, gereja-gereja termasuk sumber daya yang mereka miliki telah siap untuk mengimplementasikannya.

\section{UCAPAN TERIMA KASIH}

Penulis mengucapkan terimakasih kepada Sinode Gereja-gereja Kristen Jawa yang telah memberikan kesempatan kepada tim untuk melakukan pengabdian masyarakat di tempat ini.
Penulis juga mengucapkan terimakasih kepada Lembaga Penelitian dan Pengabdian pada Masyarakat dan Fakultas Teknologi Informasi Universitas Kristen Duta Wacana yang telah memfasilitasi dan membiayai kegiatan pengabdian ini.

\section{DAFTAR PUSTAKA}

Gay, L.R., \& Diehl, P.L. (1992). Research Methods for Business and Management. New York: Macmillan

Gill, P., Stewart, E., Treasure, E., \& Chadwick, B. (2008). Methods of data collection in qualitative research: Inverviews and Focus Groups. British Dental Journal, 204(6), 291-295.

Murumba, J., \& Omuya, E. O. (2017). Societal Implications of IT in Religion for Developing Countries. Science Journal of Education, 5(4), 144-149

Pakpahan, A.F., Siagian, V., \& Ulyreke, J.S. (2019). Perancangan dan Implementasi Aplikasi Keuangan Gereja Jemaat UNAI Berbasis Web Menggunakan Yii Framework. Jurnal Teknologi Informasi dan Komunikasi TeIKa, 9(1), 6377

Restyandito, Susanto, B., Virginia, G., \& Proboyekti, U. (2018). Perancangan Rencana Induk Pengembangan Sistem Informasi Manajemen Terpadu Sinode Gereja-Gereja Kristen Jawa. Prosiding Seminar Nasional Hasil Pengabdian kepada Masyarakat, 3(1). 188-195

Sagala, D.C., Sadikin, A., \& Irawan, B. (2018). Perancangan Sistem Pengolahan Data Jemaat Berbasis Web Pada Gereja GKPI Kota Jambi. Journal Vision Technology V-TECH, 1(2), 14-24

Shields, P.M., \& Rangarajan, N. (2013). A Playbook for Research Methods: Integrating Conceptual Frameworks and Project Management. Stillwater, OK: New Form Press.

Virginia, G., Susanto, B., Restyandito, \& Proboyekti, U. (2018). Logical Framework Analysis dan Appreciative Inquiry dalam Perencanaan Strategis Sistem Informasi Manajemen Organisasi. Prosiding Seminar Nasional Hasil Pengabdian kepada Masyarakat 3 (1). 265-271.assidy, A. (2006) A Practical Guide to Information Systems Strategic Planning, A Practical Guide to Information Systems Strategic Planning. Boca Raton: Auerbach Publications. doi: 10.1201/ 9781420048605. 